\title{
POLISSEMIAS DO EMPREENDEDORISMO NO SETOR PÚBLICO'
}

DOI: $10.14211 / 41200$

Artigo recebido em: 17/10/2014. Artigo aprovado em: 17/12/2014.

Mateus Cerqueira Anício Morais- Universidade Federal de Viçosa ${ }^{1}$ Josiel Lopes Valadares - Universidade Federal de Lavras/ Universidade Federal de Juiz de Fora ${ }^{2}$ Magnus Emmendoerfer - Universidade Federal de Viçosa ${ }^{3}$ Dany Tonelli - Universidade Federal de Lavras ${ }^{4}$

Resumo: Este artigo tem como objetivo revisar a produção científica em periódicos internacionais sobre empreendedorismo no setor público. Em termos metodológicos, fez-se uma revisão bibliográfica de artigos incluídos no sistema classificatório Web Qualis da Coordenação de Aperfeiçoamento de Pessoal de Nível Superior (CAPES). Concluiu-se que a produção científica desta temática encontra-se em processo construção e é amplamente diversificada (polissêmica). Cabe questionar o que a polissemia de termos acerca do Empreendedorismo no setor público revela. Na tentativa de abordar um novo caminho para pensar as ações do Estado, o empreendedorismo pode revelar um novo caminho metateórico pouco explorado na administração pública.

Palavras-chave: sentido, administração pública, empreendedor.

\section{ENTREPRENEURSHIP POLYSEMIES IN THE PUBLIC SECTOR}

Abstract: This article aims to understand the scientific production in international journals on entrepreneurship in the public sector. In methodological terms, was made a literature review of the searches included in the classification system Web Qualis of Coordenação de Aperfeiçoamento de Pessoal de Nível Superior (CAPES). It was concluded that the scientific production of this issue lies in a construction process and is broadly diversified (polissemic). It is fitting to ask what is the polysemy of terms about Entrepreneurship in the public sector reveal? In an attempt to address a new way to think about the state actions, the entrepreneurship can reveal a new metatheoretical path unexplored in public administration.

Keywords: sense, public administration, entrepreneur.

\footnotetext{
${ }^{1}$ E.mail: mateusaniciomorais@gmail.com

${ }^{2}$ E.mail: adm_josiel@yahoo.com.br - Endereço: Rua Treze de Outubro, 240, Centro, Lavras - MG, CEP: 37200-000.

${ }^{3}$ E.mail: magnus@ufv.br

${ }^{4}$ E.mail: danytonelli@dae.ufla.br
}

MORAIS, M.; VALADARES, J. L.; EMMENDOERFER, M.; TONELLI, D. Polissemias do empreendedorismo no setor público. Revista de Empreendedorismo e Gestão de

Pequenas Empresas, v. 4, n. 1, 2015. 
Introdução

Os anos 1970 e 1980 foram cruciais para a consolidação do pensamento neoliberal. Desde meados da década de 1970, o Welfare State, o Estado de BemEstar Social europeu estava sendo questionado quanto à sua incapacidade de garantir de forma satisfatória as demandas do Estado e da sociedade. Neste sentido, a década de 1980 representou a consolidação do pensamento neoliberal, tendo como base as influências da Escola Austríaca de economia e o monetarismo da Escola de Chicago.

Os pressupostos centrais do neoliberalismo envolviam a liberdade dos indivíduos, a questão do livre mercado, a crítica ao intervencionismo estatal preconizado pela teoria keynesiana implantada nos Estados Unidos através do new deal e a transposição de técnicas gerenciais para o setor público (PAULA, 2005).

A partir da década de 1980, essa forma de governo consolidou-se pela onda global de reformas inspiradas, principalmente no Tacherismo e Reaganismo, governos baseados na filosofia neoliberal consolidados na Inglaterra e Estados Unidos, respectivamente (DIEFENBACH, 2009). O discurso do governo empreendedor (GE) foi introduzido na administração deste contexto, ou seja, a ideia da incorporação do empreendedorismo no setor público foi alimentada pelo pensamento neoliberal e se consolidou com o surgimento do modelo de administração pública gerencial, denominado new public management (HOOD, 1991; POLLITT, 2000).

Os precursores do movimento do governo empreendedor (GE) foram os autores Osborne e Gaebler (1994) através do livro "Reinventando o Governo", publicado originalmente em 1992. Para os autores a administração pública se consolidaria como uma forma pragmática de gestão pública a partir dos conceitos do empreendedorismo. De acordo com Osborne e Gaebler (1994, p. 12), a questão do governo empreendedor parte da premissa segundo a qual "o tipo de governo que se desenvolveu durante a era industrial, com suas burocracias lentas e centralizadas, preocupado com normas e regulamentos, sujeito a cadeias de comando hierárquicas, deixou de funcionar bem".

MORAIS, M.; VALADARES, J. L.; EMMENDOERFER, M.; TONELLI, D. Polissemias do empreendedorismo no setor público. Revista de Empreendedorismo e Gestão de

Pequenas Empresas, v. 4, n. 1, 2015. 
Segundo Secchi (2009), a inspiração do GE foi a teoria moderna de administração, na qual os administradores públicos utilizariam de linguagem e ferramentas da administração privada para resoluções de problemas na esfera pública. O GE, originariamente, foi desenvolvido nos Estados Unidos no programa de governo do partido democrático nas eleições presidenciais de 1992 e depois utilizado como base para os programas de governo da administração Clinton-Gore. Também é possível observar que os ideais liberais preconizados por Friedrich August Von Haiek, em seu livro publicado em 1944, intitulado de "O caminho da servidão" e no livro do escritor Milton Friedman "Capitalismo e Liberdade", de 1962, são fundamentais para a consolidação do movimento empreendedor.

Nos últimos anos, a produção científica relacionada à noção de empreendedorismo aplicada ao setor público tem tido destaque em âmbito internacional (DIEFENBACH, 2011). No entanto, observa-se que no Brasil a produção sobre esta temática ainda é bastante incipiente. Isto pode ser justificado pelo atual estágio da administração pública brasileira e pelo caráter de novidade do governo empreendedor.

Desta forma, ao fazer uma busca pela palavra "Empreendedorismo Público" em bases como Scielo, não se encontra nenhum artigo. Deve-se ressaltar que apenas um artigo é encontrado em tal base quando da inclusão da palavra "Empreendedor Público", publicado pelos autores Valadares e Emmendoerfer (2012), na Revista de Administração Contemporânea (RAC). Encontra-se nesta lacuna, uma oportunidade de pesquisa, pois se observa que a literatura internacional tem trazido mais publicações sobre o tema empreendedorismo no setor público.

Sendo assim, questiona-se: de que forma o movimento do governo empreendedor tem sido expresso nas publicações científicas recentes? Há outros enfoques de análises sobre o tema empreendedorismo no setor público?

Diante desse contexto, este artigo tem como objetivo compreender a produção científica sobre o tema "empreendedorismo no setor público" com base em artigos internacionais.

MORAIS, M.; VALADARES, J. L.; EMMENDOERFER, M.; TONELLI, D. Polissemias do empreendedorismo no setor público. Revista de Empreendedorismo e Gestão de 


\section{Percurso metodológico}

Em termos metodológicos, realizou-se uma revisão bibliográfica sobre o tema baseada nos passos descritos a seguir. Primeiramente, o critério utilizado para a seleção dos artigos foi: estar incluído no sistema classificatório Web Qualis da Coordenação de Aperfeiçoamento de Pessoal de Nível Superior (CAPES), bem como estar disponível para acesso no portal da Instituição de Ensino Superior, a qual os autores pertencem. Justifica-se a utilização desta base de dados, pois ela é definida como um acervo que reúne a produção científica internacional, sendo também uma referência para o meio acadêmico brasileiro. Deve-se ressaltar que a pesquisa em questão baseia-se em artigos publicados em revistas internacionais devido à baixa produção teórica no Brasil.

Deve-se ressaltar que a pesquisa foi realizada no primeiro semestre de 2013. Neste tempo (aproximadamente quatro meses) procurou-se coletar, armazenar e avaliar os artigos que iriam compor a base de análise. A pesquisa foi realizada no departamento de Administração de uma Instituição de Ensino Superior do interior de Minas Gerais. Esta instituição está localizada na Zona da Mata Mineira. É importante deixar claro a localização da instituição de pesquisa, pois pode revelar o contexto de onde foi realizada a pesquisa, bem como as percepções pessoais dos profissionais quanto ao tema em estudo.

Foi adotada a técnica de análise do conteúdo do material, no qual permitiu construir uma compreensão dos resultados de forma qualitativa. Em sintonia com as ideias de Bardin (2011), complementadas por Vergara (2006), as fases de análise de conteúdo organizam-se, cronologicamente, em: pré-análise (identificação e préseleção dos documentos a partir da busca e leitura superficial); exploração do material (análise e seleção final do material por meio da leitura completa dos documentos); e tratamento dos resultados (aplicação de tratamento quantitativo com interpretação qualitativa do material selecionado na fase de exploração).

$\mathrm{Na}$ fase de pré-análise, como critérios para identificação, leitura e seleção dos artigos, foi utilizada a expressão "Public Entrepreneurship". Encontrou-se 300 artigos internacionais sobre o tema, que foram cuidadosamente analisados. Foram 
lidos os resumos e as conclusões de cada um deles, além de ser efetuada uma vistoria técnica sobre toda a estrutura do artigo a fim de encontrar algum tópico relacionado ao objeto de estudo. Ao se proceder a leitura inicial para avaliação, chegou-se a conclusão de que, em 225 artigos do conjunto encontrado, o uso da expressão "Public Entrepreneurship" estava relacionado a diversas aplicações do empreendedorismo, tais como, "empreendedorismo privado", "empreendedorismo social", "empreendedorismo civil", "empreendedorismo universitário", "empreendedorismo feminino", "empreendedorismo matrimonial", dentre outros. Em função disso, os artigos foram excluídos para fins metodológicos e viabilização desta pesquisa.

Foram considerados pela pesquisa todos os artigos que relacionavam "Public Sector" e "Entrepreneurship", isso porque muitas pesquisas apresentaram o setor público como empreendedor e outras, como um agente que fomenta o empreendedorismo. Portanto, dos 300 artigos levantados, foram selecionados para análise apenas os artigos que continham a definição de um termo que aborde de alguma forma o Empreendedorismo no Setor Público. Como resultado obteve-se 29 artigos que podem ser visualizados no apêndice deste trabalho.

\begin{tabular}{|c|c|c|c|}
\hline NÚM. & ARTIGO & $\begin{array}{l}\text { DENOMINAÇÃO DO } \\
\text { EMPREENDEDORISMO } \\
\text { NO SETOR PÚBLICO }\end{array}$ & Autores / Ano \\
\hline 1 & $\begin{array}{l}\text { A conceptual model of public sector } \\
\text { corporate entrepreneurship }\end{array}$ & $\begin{array}{l}\text { Public sector corporate } \\
\text { entrepreneurship }\end{array}$ & $\begin{array}{l}\text { Kearney, Hisrich } \\
\text { e Roche (2007) }\end{array}$ \\
\hline 2 & $\begin{array}{l}\text { An evolutionary theory of collective action: } \\
\text { Schumpeterian entrepreneurship for the } \\
\text { common good. }\end{array}$ & Public Entrepreneurship & Kuhnert (2001) \\
\hline 3 & $\begin{array}{l}\text { An exploratory research on the factors } \\
\text { stimulating corporate entrepreneurship in } \\
\text { Greek public sector }\end{array}$ & $\begin{array}{l}\text { Entrepreneurship in the } \\
\text { public sector }\end{array}$ & $\begin{array}{l}\text { Zampetakis e } \\
\text { Moustakis } \\
\text { (2010) }\end{array}$ \\
\hline 4 & $\begin{array}{l}\text { Bureaucratic entrepreneurship and } \\
\text { institutional change }\end{array}$ & $\begin{array}{l}\text { Bureaucratic } \\
\text { entrepreneurship }\end{array}$ & $\begin{array}{l}\text { Baez e Abolafia } \\
\text { (2002) }\end{array}$ \\
\hline 5 & $\begin{array}{l}\text { Caught in the net: the network- } \\
\text { entrepreneurship connection in public } \\
\text { schools }\end{array}$ & $\begin{array}{l}\text { Public school } \\
\text { entrepreneurship }\end{array}$ & Eyal (2008) \\
\hline 6 & $\begin{array}{l}\text { Corporate entrepreneurship in the public } \\
\text { sector: the dance of the chameleon }\end{array}$ & $\begin{array}{l}\text { Corporate } \\
\text { entrepreneurship in the } \\
\text { public sector }\end{array}$ & Sadler (2000) \\
\hline 7 & $\begin{array}{l}\text { Developing a public school } \\
\text { entrepreneurship inventory: theoretical } \\
\text { conceptualization and empirical }\end{array}$ & $\begin{array}{l}\text { Public school } \\
\text { entrepreneurship. Escolar } \\
\text { entrepreneurship }\end{array}$ & $\begin{array}{l}\text { Eyal e Inbar } \\
\text { (2003) }\end{array}$ \\
\hline
\end{tabular}

MORAIS, M.; VALADARES, J. L.; EMMENDOERFER, M.; TONELLI, D. Polissemias do empreendedorismo no setor público. Revista de Empreendedorismo e Gestão de 


\begin{tabular}{|c|c|c|c|}
\hline 8 & $\begin{array}{l}\text { Entrepreneurial leadership in the English } \\
\text { public sector: paradox or possibility }\end{array}$ & $\begin{array}{l}\text { Public sector } \\
\text { entrepreneurship; } \\
\text { entrepreneurship } \\
\text { leadership in the English } \\
\text { public sector }\end{array}$ & $\begin{array}{l}\text { Currie, } \\
\text { Humphreys, } \\
\text { Ucbasaran e } \\
\text { McManus } \\
(2008) \\
\end{array}$ \\
\hline 9 & Entrepreneurship, private and public & Public entrepreneurship & $\begin{array}{l}\text { Young, Francis } \\
\text { e Young (1999) }\end{array}$ \\
\hline 10 & $\begin{array}{l}\text { Exploring strategic entrepreneurship in } \\
\text { the public sector }\end{array}$ & $\begin{array}{l}\text { Entrepreneurship in the } \\
\text { public sector }\end{array}$ & $\begin{array}{l}\text { Luke e } \\
\text { Verreynne } \\
(2006)\end{array}$ \\
\hline 11 & $\begin{array}{l}\text { Fostering corporate entrepreneurship } \\
\text { through internal marketing: implications } \\
\text { for change in the public sector }\end{array}$ & $\begin{array}{l}\text { Corporate } \\
\text { entrepreneurship in the } \\
\text { public sector }\end{array}$ & $\begin{array}{l}\text { Zampetakis e } \\
\text { Moustakis } \\
(2007)\end{array}$ \\
\hline 12 & $\begin{array}{l}\text { Multidimensional entrepreneurship: } \\
\text { theoretical considerations and Swedish } \\
\text { empirics }\end{array}$ & Political entrepreneurship & Westlund (2011) \\
\hline 13 & $\begin{array}{l}\text { Peaceful and sustainable development? } \\
\text { Middle-management entrepreneurship } \\
\text { and transnational competence in China }\end{array}$ & $\begin{array}{l}\text { Bureaucratic } \\
\text { entrepreneurship }\end{array}$ & Koehn (2007) \\
\hline 14 & $\begin{array}{l}\text { Political entrepreneurship and the } \\
\text { formation of special districts }\end{array}$ & Political entrepreneurship & $\begin{array}{l}\text { Fink e Wagner } \\
(2010) \\
\end{array}$ \\
\hline 15 & $\begin{array}{l}\text { Public and private sector } \\
\text { entrepreneurship: similarities, differences } \\
\text { or a combination? }\end{array}$ & $\begin{array}{l}\text { Public sector } \\
\text { entrepreneurship }\end{array}$ & $\begin{array}{l}\text { Kearney, Hisrich } \\
\text { e Roche (2007) }\end{array}$ \\
\hline 16 & $\begin{array}{l}\text { Public entrepreneurship: toward a theory } \\
\text { of bureaucratic political power }\end{array}$ & Public entrepreneurship & Lewis (1980) \\
\hline 17 & $\begin{array}{l}\text { Public sector managers and } \\
\text { entrepreneurship in Islamic Republic of } \\
\text { Iran }\end{array}$ & $\begin{array}{l}\text { Public sector } \\
\text { entrepreneurship }\end{array}$ & $\begin{array}{c}\text { Analoui, } \\
\text { Moghimi e } \\
\text { Khanifar (2009) } \\
\end{array}$ \\
\hline 18 & $\begin{array}{l}\text { State attorneys general, entrepreneurship, } \\
\text { an consumer protection in the new } \\
\text { federalism }\end{array}$ & Political entrepreneurship & Provost (2003) \\
\hline 19 & $\begin{array}{l}\text { State entrepreneurship and dependent } \\
\text { development }\end{array}$ & State entrepreneurship & Freeman (1982) \\
\hline 20 & $\begin{array}{l}\text { The changing nature of public } \\
\text { entrepreneurship }\end{array}$ & Public entrepreneurship & $\begin{array}{c}\text { Bernier e Hafsi } \\
(2007)\end{array}$ \\
\hline 21 & $\begin{array}{l}\text { The entrepreneur: a new breed of health } \\
\text { service leader? }\end{array}$ & $\begin{array}{l}\text { Entrepreneurship in the } \\
\text { public sector }\end{array}$ & Exton (2008) \\
\hline 22 & $\begin{array}{l}\text { The economics of entrepreneurship } \\
\text { policy: introductions to the special issue }\end{array}$ & Entrepreneurship policy & Hölrl (2010) \\
\hline 23 & $\begin{array}{l}\text { The forging of judicial autonomy: political } \\
\text { entrepreneurship and the reforms of } \\
\text { William Howard Taft }\end{array}$ & Political entrepreneurship & Crowe (2007) \\
\hline 24 & $\begin{array}{l}\text { The Lisbon agenda and entrepreneurship } \\
\text { policy: governance implications from a } \\
\text { German perspective }\end{array}$ & Entrepreneurship policy & Grimm (2011) \\
\hline 25 & $\begin{array}{l}\text { The role of blame in collective action: } \\
\text { evidence from Russia }\end{array}$ & Political entrepreneurship & Javeline (2003) \\
\hline 26 & $\begin{array}{l}\text { Toward a theory of public } \\
\text { entrepreneurship }\end{array}$ & Public entrepreneurship & $\begin{array}{c}\text { Klein, Mahoney, } \\
\text { McGahan e } \\
\text { Pitelis (2010) } \\
\end{array}$ \\
\hline 27 & $\begin{array}{l}\text { Two-tiered political entrepreneurship and } \\
\text { the congressional committee system }\end{array}$ & Political entrepreneurship & $\begin{array}{c}\text { Martin e } \\
\text { Thomas (2011) } \\
\end{array}$ \\
\hline 28 & Undocumented immigrants and state & Policy entrepreneurship & Dougherty, \\
\hline
\end{tabular}

MORAIS, M.; VALADARES, J. L.; EMMENDOERFER, M.; TONELLI, D. Polissemias do empreendedorismo no setor público. Revista de Empreendedorismo e Gestão de 


\begin{tabular}{|c|l|l|c|}
\hline & $\begin{array}{l}\text { higher education policy. The politics of in- } \\
\text { state tuition eligibility in Texas and } \\
\text { Arizona }\end{array}$ & & $\begin{array}{l}\text { Nienhusser e } \\
\text { Veja (2010) }\end{array}$ \\
\hline 29 & $\begin{array}{l}\text { What drives entrepreneurial orientation in } \\
\text { the public sector? Evidence from } \\
\text { Germany's Federal labor agency }\end{array}$ & $\begin{array}{l}\text { Public Entrepreneurship, } \\
\text { mas o autor direciona sua } \\
\text { pesquisa para } \\
\text { Entrepreneurship } \\
\text { orientation in the public } \\
\text { sector }\end{array}$ & $\begin{array}{c}\text { Meynhardt e } \\
\text { Diefenbach } \\
\text { (2012) }\end{array}$ \\
\hline
\end{tabular}

QUADRO 1 - Artigos submetidos à análise

Fonte: Elaborado pelos autores (2013).

Os autores dos artigos acima abordam em suas pesquisas, várias definições e aplicações do empreendedorismo no setor público, as quais são analisadas na seção a seguir.

\section{Análise dos resultados: categorização temática}

A partir da leitura dos 29 artigos selecionados e identificados na seção anterior, observou-se que há congruências e peculiaridades nos conteúdos utilizados pelos autores dos artigos para denominar o Empreendedorismo no Setor Público (ESP). Tal observação possibilitou identificar dez sentidos ou termos, empiricamente observáveis, resultantes de diferentes manifestações do ESP, que foram captados por pesquisadores internacionais no período de 1980 a 2012. Cada um dos 10 sentidos identificados serão apresentados e discutidos a seguir.

\section{Public sector corporate entrepreneurship}

Este conceito é abordado por Kearney, Hisrich e Roche (2007) em sua pesquisa "A conceptual model of public sector corporate entrepreneurship". Segundo o autor, o "corporate entrepreneurship", é definido como o empreendedorismo dentro das organizações públicas. Nesta afirmativa, Kearney se refere a um processo organizacional que resulta em atividades inovadoras como, por exemplo, o desenvolvimento de serviços novos ou já existentes, tecnologias, técnicas administrativas e aprimoramento de estratégias. O empreendedorismo corporativo é um processo que tende a facilitar os esforços de uma organização para inovar

MORAIS, M.; VALADARES, J. L.; EMMENDOERFER, M.; TONELLI, D. Polissemias do empreendedorismo no setor público. Revista de Empreendedorismo e Gestão de

Pequenas Empresas, v. 4, n. 1, 2015. 
constantemente e se adequar eficientemente às mudanças que ocorrem tanto no ambiente interno quanto no externo.

Para o autor, o empreendedorismo no setor público é marcado pela inovação e possui duas dimensões que devem ser trabalhadas: a) Interna (a organização do setor público) que se remete à estrutura/formalidade, decisões/controle, cultura, tomada de risco e proatividade; b) Externa, que abrange o ambiente político, complexidade, munificência e mudanças provenientes do ambiente externo ao setor.

Levando em conta fatores internos ao setor público, o empreendedorismo está positivamente relacionado com organizações de estruturas orgânicas, com maior flexibilidade e decisões descentralizadas e com menor controle formal. Internamente, relaciona-se também de maneira positiva a organizações com maiores recompensas e motivações, com a cultura de flexibilidade, suporte e facilidades ao empreendedorismo, a organizações que facilitam a tomada de risco e que incentivam atitudes proativas.

No que tange aos fatores externos, o empreendedorismo se desenvolve com mais facilidade em setores que possam adaptar rapidamente às mudanças do ambiente político e a ambientes complexos. O empreendedorismo está também positivamente relacionado a ambientes de munificência, ou seja, que dão suporte ao crescimento organizacional e a ambientes com mudanças dinâmicas em constante modificação, permitindo que a organização busque sempre inovar suas atitudes. Logo, o empreendedorismo só pode ser fomentado em organizações que facilitam e encorajam a inovação.

\section{Public entrepreneurship}

O termo public entrepreneurship foi um dos termos mais conceitualizados pelos artigos encontrados na presente pesquisa. Ao todo, seis autores se desdobraram em entendê-lo, caracterizá-lo ou aplicá-lo em seus trabalhos.

Stephan Kuhnert (2001) utiliza dos conceitos do empreendedorismo Schumpeteriano para fundamentar sua teoria dinâmica da ação coletiva. Segundo 
ele, Schumpeter nunca usou o termo "public entrepreneur" (Kuhnert, 2001), mas o empreendedor conceituado por ele é aplicável ao setor público. Para o autor, "public entrepreneurship" é um fenômeno de mudança que resulta no desenvolvimento social estimulado pela ação do agente empreendedor.

O empreendedor público tende a provocar mudanças constantes no ambiente em que está inserido devido à procura por soluções inovadoras para os problemas organizacionais. Este agente não possui laços emocionais a seus cargos e à classe em que se encontra, pois é de sua característica a constante ameaça do risco tomado por suas decisões que são realizadas e regime de incertezas.

Young (1999) traz uma conceituação do termo "public entrepreneurship" de forma diferente do abordado por Kuhnert (2001). Através dos resultados de uma série de surveys aplicada em pequenas firmas manufatureiras e nas "Industrial Development Agencies (IDA's)", promovidos por Young, Francis e Young (1999) em 52 distritos de Nova York, deixam implícito que a noção de Empreendedorismo Público é relacionada à intervenção do governo no desenvolvimento dos pequenos empreendimentos.

Sem entrar em maiores discussões sobre o perfil do empreendedor público, o autor afirma que os "public entrepreneurs" são os executivos das agências fomentadoras de pequenos empreendimentos, as IDA's, as quais assistem os pequenos negócios de várias maneiras, com planos de negócio, local, construção de indústrias, parcerias e ações junto ao governo local, estatal e federal.

Outra forma de manifestação do termo "public entrepreneurship" é dada por Lewis (1980). O texto sugere que o Empreendedorismo Público é uma arte elaborada pelos "bureaucratic entrepreneurs" não eleitos, mas que se manifestam em cargos de liderança dentro do governo e auxiliam políticos eleitos. O autor exemplifica tal agente através de um estudo do comportamento de três empreendedores burocráticos dentro do governo americano. Todos eles têm em comum a geniosidade para a publicidade. Eles chegam a ter maior poder do que os próprios políticos eleitos, pois exercem a função de tomar difíceis decisões políticas que os oficiais eleitos anunciavam. São capazes de utilizar estratégias 
administrativas para alcançar interesses individuais e sobrepor seus adversários dentro da burocracia nacional.

Luc Bernier (2007) aborda um novo modelo de "public entrepreneurship". Para o autor, o empreendedorismo público é um fenômeno organizacional que ocorre de maneira cíclica dentro do setor público, ou seja, os empreendedores públicos não criam novos artefatos, não desenvolvem projetos grandiosos, mas vagarosamente reinventam suas organizações e, assim fazendo, transformam os sistemas que controlam a eficiência e a eficácia do governo de maneira gradual e cíclica. Trata-se de uma abordagem diferenciada a qual propõe 0 empreendedorismo público, se manifestando de período a período e propagando-se de forma individual para a coletiva em prol das mudanças organizacionais.

Os conceitos de Klein et al. (2010) se aproximam das inferências de Lewis (1980) quanto à aproximação do empreendedorismo no setor público com o empreendedorismo privado, mas se diferenciam amplamente quanto à cooperação do empreendedorismo privado à incorporação do conceito no contexto do setor público.

Enquanto Lewis propõe ações do governo que fomentam 0 empreendedorismo privado, Klein et al. (2010) aponta que o "public entrepreneurship" trata-se de um fenômeno gerencial no qual ideias empreendedoras são moldadas, desenvolvidas, perseguidas e institucionalizadas dentro do setor público e são colocadas em prática através de projetos que se entrelaçam com o empreendedorismo privado. Os autores argumentam que o "public Entrepreneurship" não pode substituir o "private entrepreneurship", mas é um fenômeno que o complementa.

Nesse sentido, o empreendedorismo público e privado são mutualmente dependentes e se envolvem de tal forma que se tornam interdependentes. A novidade apontada pelos autores no artigo analisado é que o empreendedorismo público deve ser estudado em quatro níveis de análise: a) regras do jogo (identificação dos objetivos, estabelecimento das regras e construção de um ambiente propício para a busca de interesses públicos e privados); b) novas organizações públicas (criação de novas organizações públicas); c) administração

MORAIS, M.; VALADARES, J. L.; EMMENDOERFER, M.; TONELLI, D. Polissemias do empreendedorismo no setor público. Revista de Empreendedorismo e Gestão de

Pequenas Empresas, v. 4, n. 1, 2015. 
criativa dos recursos públicos (a identificação, criação ou desenvolvimento pelos atores políticos de recursos que provém do âmbito público); d) propagação de ações privadas no domínio público (ações empreendedoras do setor privado que atendem os interesses públicos, garantindo instituições, normas e procedimentos).

Por fim, o último trabalho analisado que se vale do termo "public entrepreneurship" para inferir o empreendedorismo no setor público é o de Meynhardt e Diefenbach (2012). Ele sustenta a ideia de que o empreendedorismo é um fenômeno de mudanças dentro de uma organização, referindo-se à aplicação do comportamento empreendedor advindo dos conceitos do empreendedorismo privado no setor público. O diferencial da pesquisa de Meynhardt e Diefenbach (2012) diz respeito à ótica de que o empreendedorismo público resulta de uma Orientação Empreendedora dentro da organização pública.

Direcionando sua pesquisa aos "middle managers" do setor público, o autor afirma que nem sempre o estímulo ao empreendedorismo no setor público se relaciona com a criação de valor público, porque os resultados do empreendedorismo público podem ser medidos com ênfase fiscal ou social. O empreendedorismo público está diretamente relacionado com a proatividade, determinação de metas, busca de bom desempenho e eficiência na promoção da satisfação dos cidadãos.

\section{Entrepreneurship in the public sector}

A expressão "entrepreneurship in the public sector" se apresenta na literatura analisada como a aplicação direta do empreendedorismo dentro do setor público. Os trabalhos presentes neste tópico se diferenciam quanto ao foco de suas pesquisas porque os conceitos de empreendedorismo tendem a ser convergentes.

Zampetaskis e Moustakis (2010) procuram identificar quais os fatores que estimulam o empreendedorismo corporativo e quais destes são preferíveis aos servidores municipais da Grécia. O comportamento empreendedor para o autor refere-se àquelas atividades em que o servidor público utiliza combinações inovadoras de recursos a fim de criar valor. Além do mais, possui as seguintes

MORAIS, M.; VALADARES, J. L.; EMMENDOERFER, M.; TONELLI, D. Polissemias do empreendedorismo no setor público. Revista de Empreendedorismo e Gestão de

Pequenas Empresas, v. 4, n. 1, 2015. 
características: a) habilidade de transcender as limitações da burocracia; b) possui visão estratégica; c) cria um ambiente de trabalho proativo; d) ser orientado a mudanças.

Belinda Luke e Martie-Louise Verreynne (2006), em sua pesquisa "Exploring strategic entrepreneurship in the public sector' de 2006, procuram elaborar um modelo de empreendedorismo dentro do setor público. Desenvolve-se em maior relevância um novo conceito de empreendedorismo, o "strategic entrepreneurship", que ali é encontrado. O empreendedorismo no setor público é manifestado pela presença de empresas públicas com características empreendedoras provenientes do setor privado para atender demandas populacionais. Tais características são: a identificação de oportunidades, a inovação, aceitabilidade a riscos, flexibilidade, visão e crescimento.

Rosemary Exton, em 2008, defende que para o empreendedorismo no setor público ocorrer deve haver o surgimento de líderes empreendedores "entrepreneurial leaders" - os quais pensam de uma forma diferenciada, fora da caixa em relação ao local onde se encontram. Trata-se de uma nova geração de líderes que estariam aptos a gerar novas alternativas e soluções. Estes empreendedores podem ser incentivados por ações do governo, porém encontram muitos obstáculos no ambiente e nas relações de trabalho. Eles enfrentam múltiplos, ambíguos e inconsistentes objetivos dentro da organização. Enfrentam, ainda, uma hierarquia sólida dominante que não possui flexibilidade, baixos recursos, tempo útil limitado por meio de restrições forçadas por leis e costumes.

Outro obstáculo é o não apoio vindo dos executivos para iniciativas de mudanças, afetando o desempenho, a capacidade e 0 comportamento empreendedor individual dentro da organização. Para fomentar 0 empreendedorismo, a autora propõe fixar metas e objetivos de forma clara e com padrões de mensuração, além da estruturação organizacional administrativa que apoie o desenvolvimento do empreendedorismo com um sistema de recompensas por esforços individuais e coletivos.

MORAIS, M.; VALADARES, J. L.; EMMENDOERFER, M.; TONELLI, D. Polissemias do empreendedorismo no setor público. Revista de Empreendedorismo e Gestão de 


\section{Bureaucratic entrepreneurship}

Baez e Abolafia (2002) procuraram desenvolver um modelo teórico para a análise das mudanças institucionais nas organizações do setor público e para isso exploraram o papel da bureaucratic entrepreneurial action nas mudanças institucionais. Segundo eles, o "bureaucratic entrepreneurship" é resultado da ação de empreendedores, chamados de "bureaucratic entrepreneurs". Estes são agentes inovadores, adeptos ao risco e atentos ao ambiente em que estão inseridos. Através de ações empreendedoras modificam a rotina organizacional com o uso de novas informações, novas tecnologias, mudanças nas políticas governamentais, mudanças nas atividades dos stakeholders ou mudanças de fundos.

Os autores entendem que as mudanças institucionais podem ser realizadas de diversos modos, a saber, pelo keying (modo pelo qual ocorre uma mudança institucional mantendo-se suas regras); improvisation (trata-se de um improviso realizado em resposta a um problema encontrado na instituição, o qual não se pode resolver por métodos conhecidos); e o reprise (tem o objetivo de reestruturar o ambiente institucional depois de uma mudança desorganizadora resultada de um improviso).

Kohen (2007) faz uso do termo "bureaucratic entrepreneurship" de forma completamente diferente do conceito assumido por Baez et al. (2002). Com ênfase no crescimento econômico sustentável da China, o autor afirma que o empreendedorismo burocrático é parte da revolução empreendedora chinesa, o qual alcançou todos os níveis do governo. Ele é manifestado por parcerias do governo com o setor privado (government-link enterprises); pela entrada de agentes do governo no mercado, através de serviços sociais municipais; pela presença dos empreendedores na administração chinesa, atuais componentes do "entrepreneurial middle managers" que promoveram muitas mudanças nas estruturas do governo. 


\section{Public school entrepreneurship}

Eyal (2008) faz uso do conceito "public school entrepreneurship" para denotar o empreendedorismo dentro das escolas, remetendo-se à capacidade que uma instituição de ensino possui de exercer atitudes marcadas pela inovação e proatividade a fim de garantir verbas adicionais à sua receita. $\mathrm{O}$ autor comprova que embora as redes escolares (networks) (muito presentes e rígidas no governo de Israel) sejam uma forma muito vantajosa de obter informações que beneficie as instituições rumo a atitudes inovadoras, elas são uma grande barreira ao empreendedorismo.

O autor justifica esta afirmativa ao observar que estes ambientes são caracterizados pela diminuição da liberdade dos agentes públicos através da aversão a mudanças ousadas que ponha em risco a estrutura da rede. Logo, medidas interessantes para aumentar a capacidade empreendedora das instituições são propostas pelo autor. Ele recomenda ações que garantam maior grau de liberdade da instituição através da escolha cuidadosa de parcerias, do equilíbrio entre os contratos únicos e coletivos, da realização de parcerias de informações pedagógicas junto às redes e busca recursos financeiros de maneira interna, por seus próprios esforços, não dependendo de networks.

A outra pesquisa dentro do tema proposto também é de autoria de Ori Eyal, porém em parceria com Dan E. Inbar. Neste sentido, Eyal e Inbar (2003) traz em si o mesmo conceito de "school entrepreneurship" abordado acima. No entanto, através de uma pesquisa empírica, aprofundam os conceitos de empreendedorismo corporativo em escolas públicas israelenses. Evidencia-se de forma ampla que o empreendedorismo presente nestas escolas, em um sistema centralizado, é manifestado de diferentes formas e a níveis variados dentro das instituições de ensino.

É preciso dizer que o empreendedorismo escolar se apresenta em maior ou menor intensidade em função do nível de liberdade que os agentes, diretores e professores das instituições de ensino possuem dentro do sistema educacional controlado pelo Estado. Assim, como resultado, tem-se que escolas situadas na 
periferia, isto é, distantes dos centros de controle e padronização do governo, tendem a ser mais empreendedoras. Essa liberdade é concedida pela posição geosocial das instituições.

Vale destacar que dois fatores são importantes para a mensuração do empreendedorismo dentro das escolas públicas: a) a proatividade exibida pelo diretor, que seria a autoridade institucional, ou seja, seu nível motivacional e práticas inovadoras, que são determinantes no desenvolvimento do empreendedorismo; b) a capacidade inovadora da própria organização, evidenciada pelo perfil empreendedor presente no corpo docente da instituição. Portanto, percebe-se que o empreendedorismo escolar se manifesta de maneira corporativa no setor público israelense, sendo diretamente ligado ao grau de liberdade das instituições de ensino. Corporate Entrepreneurship in The Public Sector

Sadler (2000) traz em seu artigo o conceito de que o empreendedorismo no setor público é um desejo organizacional de mudança, adaptação, afeição ao risco e inovação, que é utilizado para explorar oportunidades e criar valor. É evidenciado que organizações empreendedoras do setor público sobrevivem em ambientes turbulentos, tendem a tomar decisões de forma coletiva e a utilizar pouco a consulta pública ao tomá-las, criando assim um ambiente que proporcione autonomia aos seus grupos, além de serem também focada em resultados. Estes atos facilitam com que a cultura empreendedora se instale dentro da organização.

O autor especifica que "middle-managers" e "front-line workers" tendem a serem os mais empreendedores dentro de uma organização. Porém, aponta que processos burocráticos, exposição de projetos frustrados na mídia, baixa competição, baixo controle dos recursos, regulação massiva dos custos, julgamento constante das verbas e resultados, multiplicidade e ambiguidade de objetivos, contínuo retorno financeiro governamental, necessidade constante de consulta ao governo, intervenção política na administração, emprego restrito de políticas e escalas rígidas de salários, aversão ao risco, bônus ineficientes aos empreendedores e sistema de punição aos erros e fraca disciplina financeira, são fatores presentes no setor público e limitadores da cultura empreendedora.

MORAIS, M.; VALADARES, J. L.; EMMENDOERFER, M.; TONELLI, D. Polissemias do empreendedorismo no setor público. Revista de Empreendedorismo e Gestão de 
Para solucionar tais problemas e proporcionar o empreendedorismo corporativo no setor público, deve-se investir, segundo o autor, no claro entendimento dos objetivos, em grupos de trabalho coesos, decisões autônomas, bônus efetivos aos empreendedores e ausência de punições aos erros, pouca intervenção política, rotatividade de pessoal moderada, foco em resultados, decisões participativas, ambiente competitivo.

Zampetaskis e Moustakis (2007) atribuem o mesmo significado para "Corporate Entrepreneurship in the Public Sector" ao afirmar que o Empreendedorismo Público refere-se à presença de práticas empreendedoras no setor público. Isso ocorre através do empreendedorismo corporativo, que é a aplicação da cultura empreendedora dentro da organização pública que traz consigo a geração de ideias e inovações as quais resultam em valor agregado à população através de produtos, serviços e processos. Porém, os autores apontam de forma mais abrangente a importância do "internal marketing" na geração de uma cultura empreendedora dentro do setor público. Neste sentido, o autor evidencia a importância do incentivo do marketing interno do setor público para que o foco seja a melhoria da condição motivacional dos colaboradores.

Nesse contexto, o endomarketing torna-se um aliado à promoção de um clima mais favorável para tomada de decisão e alcance dos resultados da organização pública. Alguns meios de implantar o "corporate entrepreneurship" através do marketing interno são: a) rotação de serviço: o servidor tem uma rotatividade de serviços, trabalhando de tempos em tempos em diferentes setores ou departamentos; b) prêmios por desempenho: remuneração monetária em reconhecimento aos reforços de um trabalhador ou um grupo; c) treinamento: treinamento interno para promover novas habilidades; d) trial period: período probatório em que o servidor é submetido a um programa de trainee, que desenvolveria suas habilidades.

MORAIS, M.; VALADARES, J. L.; EMMENDOERFER, M.; TONELLI, D. Polissemias do empreendedorismo no setor público. Revista de Empreendedorismo e Gestão de 


\section{Public sector entrepreneurship}

Currie et al. (2008) buscam explorar a possibilidade de aplicação da liderança empreendedora no setor público inglês pela Labour Government's Modernization Agenda, examinando também como o empreendedorismo se manifesta neste contexto. Neste artigo, os autores relacionam o termo "public sector entrepreneurship" com "entrepreneurship leadership in the english public sector", isto porque, segundo o texto, o empreendedorismo é implantado dentro do setor público inglês por meio de líderes empreendedores que trabalham a fim de atender as demandas que thes são impostas. O autor dá indícios de que o empreendedorismo tem maior facilidade de se apresentar em setores independentes e com características privadas dentro do Estado.

Assim, o public sector entrepreneur identifica oportunidades no mercado sobre uma ótica política, aperfeiçoa a performance organizacional aumentando o potencial de inovação no setor público, lida com os stakeholders de uma forma que ambos permitam riscos e também realiza da melhor forma a gestão dos recursos do setor público.

Segundo Kearney, Hisrich e Roche (2009), o empreendedorismo é o fenômeno fomentador da eficiência, flexibilidade e da administração adaptável dentro de ambientes de constante turbulência e competitividade. Ele é o gerador de inovações, tanto no setor público como no privado. O texto argumenta que enquanto existem várias similaridades entre a aplicação do empreendedorismo no setor público e no setor privado, muitas diferenças são manifestadas quanto aos fatores chaves do empreendedorismo nessas organizações, tais como a forma de manifestação de inovações, proatividade e tomada de risco, existindo divergências quanto ao ambiente político, à complexidade, munificência, dinamismo, controle na estrutura, nas formalidades, nas motivações e nas mensurações do desempenho das ações empreendedoras.

Analoui, Moghimi e Khanifar (2009) traz em suas pesquisas um conceito abrangente do termo "public sector entrepreneurship" com o foco nas implicações do Empreendedorismo no Setor Público sobre as ações governamentais israelenses.

MORAIS, M.; VALADARES, J. L.; EMMENDOERFER, M.; TONELLI, D. Polissemias do empreendedorismo no setor público. Revista de Empreendedorismo e Gestão de 
Os autores relacionam "Public Sector Entrepreneurship, Entrepreneurship on public Organizations, Governement Entrepreneurship e Entrepreneurial state”, definindo que o Empreendedorismo no Setor Público tende a definir o crescimento, a produtividade e a competitividade de suas economias através da busca pelas oportunidades e pelo direcionamento dos negócios públicos e privados.

\section{Political entrepreneurship}

Juntamente com o "public entrepreneurship", o termo "political entrepreneurship" foi a expressão mais utilizada pelos autores para nomear o empreendedorismo presente nas organizações públicas. Ao todo, seis artigos fizeram uso dessa expressão para diferentes finalidades.

Para Westlund (2011), o "political entrepreneurship" é o fenômeno presente nas organizações públicas. É responsável por uma cadeia de atividades, nas quais se incluem a busca e avaliação de oportunidades, e arrecadação de fundos. Ocorre em qualquer organização onde existe disputa de poder e influências. Está mais presente em governos locais, fora das áreas metropolitanas porque intervém criando empreendimentos. Trata-se de uma forma compensatória da ausência de mercados fortes. Portanto, ele é negativamente relacionado com o empreendedorismo econômico que se manifesta no mercado como fomentador político das startups. Eles são opostos uns aos outros e são resultados da ausência do outro.

Para Fink e Wagner (2010), o empreendedorismo político é o gênesis de empreendimentos no setor público, fornecendo produtos que atendam a demandas sociais específicas, tais como tratamento de água, controle de doenças, de pragas, museus, aeroportos, reservas ambientais, etc., conhecidos como "special districts" do governo. Os distritos especializados do governo são criados pelos empreendedores políticos e tendem a contemplar necessidades sociais não atendidas no plano geral do governo.

É importante ressaltar que, segundo o texto, tais demandas são atendidas devido à atenção dos empreendedores aos acontecimentos a sua volta e à 
sensibilidade que eles têm em reconhecer oportunidades de ganhos pessoais, que acabam garantindo ganhos sociais.

Já Provost (2003) procura explorar de forma ampla as motivações existentes para os procuradores gerais do estado se tornarem empreendedores políticos. Segundo o autor, o "political entrepreneurship" gira em torno da capacidade dos policymakers de explorar certas condições políticas e econômicas a fim de implementar programas novos e inovadores, modificando assim os resultados das políticas públicas. Trata-se de atitudes empreendedoras dentro de organizações públicas.

Crowe (2007) define "political entrepreneurship" como um conjunto de ações políticas tomadas por líderes criativos, engenhosos e oportunistas que habilidosamente manipulam a política de tal forma que resultam na criação de novas políticas ou agências burocráticas, na criação de novas instituições ou na transformação de alguma existente.

“Political Entrepreneurship" para a Russa Debra Javeline (2003), em seu estudo "The Role of Blame in Collective Action: Evidence from Russia", possui uma aplicação bem diferenciada sobre o termo. Segundo a autora, o empreendedorismo político é manifestado pela articulação de empreendedores que mobilizam multidões a protestos. Isto porque, segundo ela, a sociedade como um todo, em momentos de injustiça e crises no Estado, possui dificuldade de canalizar seus esforços e atribuir culpa aos verdadeiros responsáveis da injustiça latente, a fim de realizar uma manifestação reivindicadora.

O political entrepreuner facilita os protestos criando um incentivo ao cidadão ao afetar positivamente sua satisfação, gerando um sentimento de obrigação ou orgulho de participar do movimento. Tais empreendedores assumem os custos da ação coletiva arrecadando informações, detectando o culpado e convencendo os agentes, principalmente aqueles que possuem a identificação do culpado de forma ampla ou vaga, a realizar o movimento coletivo. Portanto, pelo texto, o Political Entrepreneur se coloca como líder político que persegue seus próprios interesses dentro da carreira política.

MORAIS, M.; VALADARES, J. L.; EMMENDOERFER, M.; TONELLI, D. Polissemias do empreendedorismo no setor público. Revista de Empreendedorismo e Gestão de 
Por fim, a pesquisa de Martin e Thomas (2011) conceitua o empreendedorismo político como a ação de indivíduos dentro do Estado que promove mudanças políticas e estruturais. Segundo o texto "political entrepreneurs" são os agentes políticos que articulam políticas públicas dentro do governo. Existem dois tipos de political entrepreneur: "policy entrepreneur" e "institutional entrepreneur". Os "policy entrepreuners" exercem o papel de identificar problemas políticos, mobilizar coligações de suporte e implementar mudanças políticas dentro das regras institucionais. $O$ autor argumenta que sendo o "policy entrepreuner" limitado pelas regras institucionais, é forçado a procurar inovações a níveis maiores dentro da estrutura estatal a fim de que seus objetivos políticos sejam alcançados, e, desta forma, se desenvolve o "institutional entrepreneur", que se move em direção a inovações institucionais que cooperem com as inovações políticas futuras.

\section{State entrepreneurship}

Sobre o conceito de "state entrepreneurship", John Freeman (1982), em sua pesquisa "State Entrepreneurship and Dependent Development", a mais antiga analisada qualitativamente, define que o empreendedorismo estatal nasce através do nacionalismo e da necessidade da elite nacional em fazer o país crescer economicamente. Trata-se de uma tríplice aliança entre o Estado, o capital local e multinacional, que através de uma política pública, transformam empresas produtivas em órgãos públicos, operando em concordância com os padrões do mercado.

O processo de empreendedorismo estatal se dá à medida que o governo controla a atividade produtiva de uma empresa e quando os agentes do governo passam a substituir os empreendedores do setor privado. Segundo ele, esse tipo de política ocorre na maioria das vezes em países em industrialização, de Terceiro Mundo. Trata-se de uma das maneiras mais efetivas das quais um Estado pode valer-se a fim de fomentar o crescimento econômico, porém de forma dependente do capital e da tecnologia advinda do primeiro mundo.

MORAIS, M.; VALADARES, J. L.; EMMENDOERFER, M.; TONELLI, D. Polissemias do empreendedorismo no setor público. Revista de Empreendedorismo e Gestão de

Pequenas Empresas, v. 4, n. 1, 2015. 


\section{Entrepreneurship policy}

O termo "entrepreneurship policy" é abordado por Hölrl (2010) como políticas públicas que fomentam o empreendedorismo na economia. Para o autor, tais políticas visam incentivar o "self-employment", ou seja, a abertura de novos negócios através da redução de barreiras à entrada e ao crescimento das firmas no mercado, de financiamentos, de subsídios à inovação e por meio de leis que diminuam os custos econômicos e sociais das falências. Em conclusão, a pesquisa coloca que através das políticas empreendedoras, o mercado se torna mais robusto e a produção aumenta, gerando bem-estar social via crescimento econômico.

Com o mesmo conceito, porém de forma mais ampla, Grimm (2011) afirma que "entrepreneurship policy" é uma política empreendedora com o objetivo de promover novas empresas, estimular o comportamento empreendedor e os potenciais dos cidadãos no mercado. Tais políticas têm a característica de criar um ambiente propício para o estímulo do empreendedorismo através de projetos no campo do emprego, da infraestrutura, da tecnologia da informação, pesquisa, capital humano, desenvolvimento de empresas, inclusão social e desenvolvimento sustentável. A conclusão apresentada pelo autor é de que tais políticas geram inovação, crescimento e emprego na economia.

\section{Policy entrepreneurship}

Segundo Dougherty, Nienhusser e Vega (2010), o termo "policy entrepreneurship" mantém a característica apresentada no estudo do termo "entrepreneurship policy" de ser uma política pública, porém, nesse caso, se manifesta de forma diferente. Segundo os autores, "Policy Entrepreneurship" são políticas públicas inovadoras realizadas pelo setor público. Diferentemente do conceito apresentado acima, que define a política empreendedora como uma política pública que gera o empreendedorismo fora da maquina pública, ou seja, no mercado, Dougherty, Nienhusser e Vega (2010) demonstram que a política 
empreendedora é aquela política resultante do empreendedorismo dentro da organização pública.

Os "Policy Entrepreneurs" são os agentes públicos que elaboram a política empreendedora, assumindo quatro papéis principais em sua elaboração, a saber: definir e apontar os problemas sociais, construir coalizões políticas, tomar vantagem de aberturas políticas para promover mudanças e definir soluções viáveis aos problemas sociais. O exemplo analisado no texto é a política de legalização de imigrantes do estado do Texas, EUA, tida como empreendedora por trazer pacificação social e benefícios econômicos ao Estado.

\section{Considerações finais}

Neste artigo, pôde-se perceber a amplitude do tema empreendedorismo aplicado ao setor público em artigos internacionais. Observou-se, através da análise das conclusões dos artigos, que a área de estudos sobre empreendedorismo no setor apresenta um amplo crescimento nos últimos anos, com destaque para as discussões com enfoque no fator político do empreendedor. O processo de estruturação do campo teórico pôde ser constatado pela existência de diversos termos (polissemia) utilizados para denominar o empreendedorismo no setor público, cada um apresentando muitos aspectos divergentes entre si no que se refere ao conceito, características e aplicações do empreendedorismo, demonstrando que não existe até então um consenso sobre sua definição geral.

Em contrapartida, pôde-se perceber que na maioria dos artigos, a noção de empreendedorismo no setor público teve sua origem advinda do setor privado (MEYNHARDT; DIEFENBACH, 2012). As características empreendedoras sinalizadas pelo modelo de Kearney, Hisrich e Roche (2007) de que 0 empreendedorismo no setor público se refere a um processo de aperfeiçoamento que resulta em atividades inovadoras, como o desenvolvimento de serviços novos ou já existentes, tecnologias, técnicas administrativas e aprimoramento de estratégias, parecem estar implícitas em todas as pesquisas estudadas.

MORAIS, M.; VALADARES, J. L.; EMMENDOERFER, M.; TONELLI, D. Polissemias do empreendedorismo no setor público. Revista de Empreendedorismo e Gestão de 
São diversas as formas pelas quais o empreendedorismo se apresenta no setor público. Na presente pesquisa evidenciou-se sua manifestação através de uma cultura empreendedora dentro das organizações públicas (SADLER, 2000; KEARNEY, 2007; ZAMPETAKIS; MOUSTAKIS, 2007; EYAL, 2008; ZAMPETAKIS; MOUSTAKIS, 2010; MEYNHARDT; DIEFENBACH, 2012), nos movimentos sociais (KUHNERT, 2001; JAVELINE, 2003) e em parcerias público-privadas (KLEIN et al., 2010; KOHEN, 2007). Manifesta-se também através das políticas públicas, seja como fomento ao empreendedorismo no setor público como indicaram Young, Francis e Young (1999), Hölr (2010) e Grimm (2011), ou como política inovadora dentro do setor público (PROVOST, 2003; DOUGHERTY, NIENHUSSER; VEGA, 2010). Também pode se observar o empreendedorismo sendo manifesto pela criação de empresas estatais, como afirmado nas pesquisas de Freeman (1982), Luke e Verreynne (2006), Alanoue et al. (2009), Fink e Wagner (2010) e Westlund (2011).

Deve-se destacar que o tema empreendedorismo no setor público ainda se apresenta como uma área muito ampla dentro da administração, com diversas definições e poucos consensos entre os pesquisadores da área. Há debates intensos que definem pontos divergentes entre as pesquisas, contudo nenhum dos trabalhos analisados se debruçou em confrontar os diferentes conceitos do tema. Neste ponto, é preciso ressaltar que a baixa produção científica ainda não permitiu a consolidação de um corpo teórico da área.

Desta forma, o empreendedorismo no setor público tem se apresentado através de diversos termos e noções, de formas não consensuais, mas que se vinculam aos enfoques econômico (SCHUMPETER, 1954) e/ou comportamental (MCCLELAND; BURNHAM, 1976) presentes na teoria do empreendedorismo. Muitas pesquisas têm procurado criar um conceito de empreendedorismo no setor público dentro das onze denominações apresentadas nesta pesquisa. Entretanto, há discrepância sobre qual é a mais adequada definição de empreendedorismo no setor público.

Diante dos dados analisados, é importante dizer que apesar da variedade dos termos, em muitos deles o significado a que se remete é o mesmo. Este fato

MORAIS, M.; VALADARES, J. L.; EMMENDOERFER, M.; TONELLI, D. Polissemias do empreendedorismo no setor público. Revista de Empreendedorismo e Gestão de

Pequenas Empresas, v. 4, n. 1, 2015. 
pode estar alinhado com a influência do pensamento neoliberal evidenciado na perspectiva da New Public Management no setor público. Neste sentido, observa-se que a incorporação do empreendedorismo no setor público vai além das questões terminológicas, uma vez que os termos revelam, de certa forma, a mesma questão em sim.

Diante desse contexto, torna-se importante mencionar que a polissemia encontrada revela que não se trata de conceitos diferentes, mas de diferentes interpretações sobre o mesmo conceito. Em outras palavras, o empreendedorismo no setor público torna-se espaço-temporalmente localizado. Portanto, a realidade socioeconômica e cultural influencia a produção científica analisada sobre o tema, já que o enfoque que cada artigo tem pode estar relacionado com a realidade social imediata da pesquisa.

Neste sentido, cabe questionar como pergunta final deste trabalho: o que a polissemia de termos acerca do Empreendedorismo no setor público revela? $\mathrm{Na}$ tentativa de abordar um novo caminho de pensar as ações do Estado, a noção de empreendedorismo pode revelar um novo caminho metateórico pouco explorado na administração pública. Conforme se pode constatar, o elemento norteador das discussões do empreendedorismo no setor público ainda é a ideologia do governo empreendedor, amplamente difundida pelo pensamento liberal e consumada por meio de obras, como a de Osborne e Gaebler (1994).

Por fim, faz-se um alerta aos pesquisadores da área para buscar novas maneiras de compreender este termo na gestão pública, atentando para as possibilidades objetivas de trabalhar as racionalidades substantivas presentes neste termo.

\section{Referências:}

ANALOUI, F.; MOGHIMI S. M.; KHANIFAR H. Public sector managers and entrepreneurship in Islamic Republic of Iran, Journal of Management Development, v. 28, n. 6, p. $522-532,2009$.

MORAIS, M.; VALADARES, J. L.; EMMENDOERFER, M.; TONELLI, D. Polissemias do empreendedorismo no setor público. Revista de Empreendedorismo e Gestão de 
BAEZ, B.; ABOLAFIA, M. Y. Bureaucratic entrepreneurship and institutional change: a sense making approach. Journal of Public Administration Research and Theory, v. 12, n. 4, p. 525-552, 2002.

BARDIN, L. Análise de conteúdo. São Paulo: Edições 70, 2011.

BERNIER, L; HAFSI, T. The changing nature of public entrepreneurship. Public Administration Review, v. 67, n. 3, p. 488-503, 2007.

CROWE J., The forging of judicial, political entrepreneurship and the reforms of william howard taft, The Journal of Politics, v. 69, n. 1, p. 73-87, fev. 2007.

CURRIE, G.; HUMPHREYS, M.; UCBASARAN, D.; MCMANUS, S. Entrepreneurial leadership in the English public sector: Paradox or possibility? Public Administration, v. 86, n. 4, p. 987-1008, 2008.

DIEFENBACH, F. E. Entrepreneurship in the public sector: When middle managers create public value. Wiesbaden. Gabler Research, 2011. p. 165-166.

DIEFENBACH, T. New public management in public sector organizations: The dark sides of managerialistic enlightenment. Public Administration, v. 87, n. 4, p. 892909, 2009.

DOUGHERTY K. J.; NIENHUSSER H. K, VEGA B. E. Undocumented immigrants and state higher education policy: The politics of in-state tuition eligibility in Texas and Arizona. The Review of Higher Education, v. 34, n. 1, p. 123-173, 2010.

EXTON R, The entrepreneur: a new breed of health service leader? Journal of Health Organization and Management, v. 22, n. 3, p. 208-222, 2008.

EYAL O., Caught in the net: the network-entrepreneurship connection in public schools, International Journal of Educational Management, v. 22, n. 5, p. 386398, 2008.

EYAL, O.; INBAR, D. E. Developing a public school entrepreneurship inventory: Theoretical conceptualization and empirical examination. International Journal of Entrepreneurial Behavior \& Research, v. 9, n. 6, p. 221-244, 2003.

FINK A., WAGNER R. E., Political entrepreneurship and the formation of special districts. European Journal of Law and Economics, Forthcoming, 2010.

MORAIS, M.; VALADARES, J. L.; EMMENDOERFER, M.; TONELLI, D. Polissemias do empreendedorismo no setor público. Revista de Empreendedorismo e Gestão de

Pequenas Empresas, v. 4, n. 1, 2015. 
FREEMAN J. R., State entrepreneurship and dependent development, American Journal of Political Science, v. 26, n. 1, p. 90-112, fev. 1982.

GRIMM H. M., The Lisbon agenda and entrepreneurship policy: Governance implications from a German perspective, Public Administration, v. 89, n. 4, p. 1526-1545, 2011.

HÖLZL, W. The economics of entrepreneurship policy: Introduction to the special issue, Journal of Industry, Competition and Trade, v.10, n. 3-4, p 187-197, 2010.

HOOD, C. A public management for all seasons? Public Administration, v. 69, n. 1, p. 3-19, 1991.

JAVELINE, D. The role of blame in collective action: Evidence from Russia, The American Political Science Review, v. 97, n. 1, p. 107-121, fev. 2003.

KEARNEY, C., HISRICH, R. ROCHE, F. Facilitating public sector corporate entrepreneurship process: a conceptual model, Journal of Enterprising Culture, v. 15, n. 3, p. 275-99, 2007.

- Public and private sector entrepreneurship: Similarities, differences or a combination? Journal of Small Business and Enterprise Development, v. 16, n. 1, p. 26-46, 2009.

KLEIN P. G., MAHONEY J. T., MCGAHAN A. M., PITELIS C. N. Toward a theory of public entrepreneurship. European Management Review, v. 7, p. 1-15, 2010.

KOHEN P. H., Peaceful and sustainable development? Middle-management entrepreneurship and transnational competence in China. East Asia, v. 24, p. 251263, 2007

KUHNERT S., An evolutionary theory of collective action: Schumpeterian entrepreneurship for the common good. Constitutional Political Economy, v. 12, p. 13-29, 2001.

LEWIS, E., Toward a theory of bureaucratic political power. Bloomington, Indiana University Press, 1980. 274 pp.

LUKE, B.; VERREYNNE, M.L. Exploring strategic entrepreneurship in the public sector. Qualitative Research in Accounting \& Management, v. 3, n. 1, p, 4-26, 2006.

MORAIS, M.; VALADARES, J. L.; EMMENDOERFER, M.; TONELLI, D. Polissemias do empreendedorismo no setor público. Revista de Empreendedorismo e Gestão de

Pequenas Empresas, v. 4, n. 1, 2015. 
MARTIN A., THOMAS D. Two-tiered political entrepreneurship and the congressional committee system. Public Choice Received, 2011.

MCCLELLAND, D. C.; BURNHAM, D. H. Power is the great motivator. Harvard Business Review, March-April, 100-110, 1976.

MEYNHARDT T., DIEFENBACH F. E. What drives entrepreneurial orientation in the public sector? Evidence from Germany's federal labor agency, Journal of Public Administration Research and Theory Advance Access published, v. 19, Abr. 2012.

OSBORNE, D; GAEBLER,T. Reinventando o governo: como o espírito empreendedor está transformando o setor público. Brasília: MH Comunicação, 1994.

PAULA, A. P. P. de. Por uma nova gestão pública: limites e potencialidades da experiência contemporânea. Rio de Janeiro: FGV, 2005.

PROVOST ,C. State attorneys general, entrepreneurship, and consumer protection in the new federalism, Publius: The Journal of Federalism, v. 33, n.2, 2003.

POLLITT, C. Is the emperor in his underwear? An analysis of the impacts of Public Management Reform, Public Management, v. 2, n. 2, p. 181-99, 2000.

SADLER, R.J. Corporate entrepreneurship in the public sector: the dance of the chameleon. Australian Journal of Public Administration, v. 59, n. 2, p.25-43, 2000.

SCHUMPETER, J.A. History of Economic Analysis. Nova York: Oxford University Press, 1954.

SECCHI, Leonardo. Modelos orgnanizacionais e reformas da administração pública. Revista de Administração Pública, RAP - Rio de Janeiro, v. 43, n. 2, p.347-369, mar./abr. 2009.

VALADARES, J. L.; EMMENDOERFER, M. L. Cargos de Livre Nomeação: Reflexões com Base no Empreendedor Público em um Estado-Membro do Brasil. Revista de Administração Contemporânea (RAC), Rio de Janeiro, v. 16, n. 5, art. 5, p. 723-743, Set./Out. 2012.

MORAIS, M.; VALADARES, J. L.; EMMENDOERFER, M.; TONELLI, D. Polissemias do empreendedorismo no setor público. Revista de Empreendedorismo e Gestão de

Pequenas Empresas, v. 4, n. 1, 2015. 


\section{A Revista da ANEGEPE \\ www.regepe.org.br}

VERGARA, S. C. Métodos de pesquisa em administração. 2. ed. São Paulo: Atlas, 2006.

WESTLUND H.. Multidimensional entrepreneurship: theoretical considerations and Swedish empirics, Regional Science Policy \& Practice, v. 3, n. 3, ago. 2011.

YOUNG, R. C; FRANCIS J. D; YOUNG, C. H., Entrepreneurship, Private and Public, Lanham, MD: University Press of America, 1999. 253 pp.

ZAMPETAKIS L. A., MOUSTAKIS V. S., Fostering corporate entrepreneurship through internal marketing: Implications for change in the public sector, European Journal of Innovation Management, v. 10, n. 4, p. 413-433, 2007.

ZAMPETAKIS L. A., MOUSTAKIS V. S., An exploratory research on the factors stimulating corporate entrepreneurship in the Greek public sector. International Journal of Manpower, v. 31, n. 8, p. 871-887, 2010.

\section{'Agradecimentos:}

À Coordenação de Aperfeiçoamento de Pessoal de Nível Superior (CAPES) pelas bolsas de mestrado, doutorado e de estágio pós-doutoral (Processo BEX-1254/14-6) oferecidas, respectivamente, aos três primeiros autores, que contribuíram para a geração deste artigo. 